This document is the unedited Author's version of a Submitted Work that was subsequently accepted for publication in Langmuir, copyright (C) American Chemical Society after peer review. To access the final edited and published work see

https://pubs.acs.org/doi/10.1021/acs.langmuir.0c02373. 


\section{Chiral Templating of Polycarbonate Membranes by Pinene Using Modified Atomic Layer Deposition}

\section{Approach}

Libuše Brožováa ${ }^{a}$, Raul Zazpe ${ }^{b, c}$, Miroslav Otmar ${ }^{a}$, Jan Přikryl ${ }^{b}$, Roman Bulánek ${ }^{d}$, Jan Žitka ${ }^{a}$,

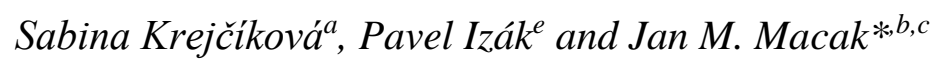

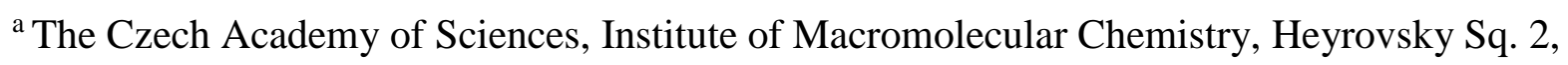
16206 Prague 6, Czech Republic

${ }^{\mathrm{b}}$ Center of Materials and Nanotechnologies, Faculty of Chemical Technology, University of Pardubice, Nam. Cs. Legii 565, 53002 Pardubice, Czech Republic.

${ }^{c}$ Central European Institute of Technology, Brno University of Technology, Purkynova 123, 612 00 Brno, Czech Republic

${ }^{\mathrm{d}}$ Department of Physical Chemistry, Faculty of Chemical Technology, University of Pardubice, Studentska 573, 53210 Pardubice, Czech Republic

${ }^{\mathrm{e}}$ The Czech Academy of Sciences, Institute of Chemical Process Fundamentals, Rozvojova 135, 16502 Prague 6 - Suchdol, Czech Republic

Keywords: chiral templating, polycarbonate, trimethylaluminum, enantiomer, pinene 


\begin{abstract}
In this article, a chiral templating of polycarbonate (PC) membrane by (-)- $\alpha$-pinene using the atomic layer deposition (ALD) approach is investigated. The templating with enantiomer of (-)a-pinene, used as a case compound, was performed either on the original commercial PC membrane or on the PC membrane with a beforehand deposited $\mathrm{Al}_{2} \mathrm{O}_{3}$ layer. The efficiency of the templating was assessed by a difference of membrane ability to adsorb/absorb (-)- $\alpha$-pinene, $(+)-$ $\alpha$-pinene and their racemic mixture, using a very sensitive gas sorption analyzer. The results clearly show that the solution-diffusion mechanism rather than the sieving mechanism applied for adsorption/absorption of $(-/+)$ - $\alpha$-pinene enantiomers, which have the same size of the molecule. The PC membrane with the pre-deposited $\mathrm{Al}_{2} \mathrm{O}_{3}$ before the (-)- $\alpha$-pinene templating shows a significantly higher sorption of $(-)$ - $\alpha$-pinene compared to $(+)-\alpha$-pinene and racemate, which clearly demonstrates presence of a chiral recognition effect.
\end{abstract}


Introduction

Many molecules in living organisms are chiral. The individual enantiomers of chiral compounds often differ with their biological properties; e.g., in the case of some terpenoids, the enantiomers can be distinguished by a specific flavor or smell. If one of the enantiomers has a therapeutic effect, the other can be inactive or even toxic. ${ }^{1-3}$ In contrast to the current separation techniques, the uniqueness of chiral separation stems from the fact, that the individual enantiomers exhibit identical chemical and physical properties, and therefore some asymmetric surroundings must be created to achieve their distinction (except for self-disproportionation of enantiomers phenomenon). ${ }^{4,5}$ For this reason, the enantioseparation still remains a very challenging and difficult task in the production of biologically active compounds. ${ }^{6,7}$

Nowadays, approximately $60 \%$ of all available drugs are chiral, $75 \%$ of them are used as racemates, and $25 \%$ as enantiomerically pure. ${ }^{8}$ In 1992, the Food and Drug Administration issued the policy that all new drugs must be tested for the biological and toxicological properties in all their forms (individual enantiomers and their metabolites). Therefore, there has been a continuous effort to reformulate chiral drugs as the single enantiomers.

Despite the enormous effort devoted to asymmetric synthesis, chiral separation is still a widely used method for obtaining optically pure compounds. Among various enantioseparation methods (preparative HPLC, kinetic resolution, simulated moving bed, etc.), ${ }^{9}$ a chiral separation through polymer membranes has recently emerged. This technology seems to be advantageous for its low financial cost, continuousness and easy scalability of the process. ${ }^{10-12}$ However, at the moment, any suitable membranes applicable for the practical separation of racemic mixtures in chemical 
industries, have not yet appeared. Therefore, the development of new materials for the membrane separation of racemic mixtures is highly desired.

To fulfill the above described needs, flat non-porous polymer or microporous surface coated membranes as well as tubular or hollow fiber modules have been employed. ${ }^{13}$ The general principles known from the HPLC and GC chiral separations and from the biochemical enantioseparation processes have been applied also for the design of various membrane materials. Thus, materials with a primary and/or secondary chiral structure (e.g. helix) such as ((poly(triphenylmethyl methacrylate)), polysaccharides, ${ }^{14,15}$ proteins, cyclodextrins, ${ }^{16-19}$ and imprinted polymers ${ }^{20,21}$ have been used to prepare chiral membranes by direct synthesis or for a modification of achiral membranes. Another approach is based on the incorporation of chiral selectors into a micro-porous solid, e.g. supported liquid membranes, ${ }^{22-28}$ where chiral organic molecules in a liquid form (as a solution or as a chiral liquid) are fixed by physical forces to a solid substance.

The aim of this work was to exploit the potential of a chiral templating of polycarbonate membranes with a suitable chiral molecule using atomic layer deposition approach.

Polycarbonate membranes (PCM) with high aspect ratio were selected as suitable substrates for the chiral templating. Polycarbonate is an amorphous (non-crystalline) polymer, which is formed by the interfacial reaction of bisphenol A and phosgene. The arrangement of the individual monomers in the PC turns the polymer chains into intertwined balls. The large number of benzene rings in the backbone causes rigidity of the chains. ${ }^{29,30}$ These entangled rigid chains form cavities with a suitable shape for the penetration and imprint of template molecules. 
As a model chiral template ${ }^{31},(-)-\alpha$-pinene ${ }^{32}$ was selected due to its optimal volatility and low financial cost. It was templated within PCM using ALD either on an intact PCM surface or on a PCM surface ALD pre-coated with of aluminum oxide $\left(\mathrm{Al}_{2} \mathrm{O}_{3}\right)$.

ALD is a well established deposition method, which enables a conformal and uniform coating or decoration of different nanostructures, such as one-dimensional nanopores and nanotubes. ${ }^{33,34}$ In order to essentially modify the surface of the PCM with (-)- $\alpha$-pinene molecules, molecule of ()- $\alpha$-pinene was repetitively dosed within PCM using traditional ALD sequence (i.e. pulse, and purge). However, it was not the true ALD process that requires counter reactions of two precursors, covalent bonding, self-terminating mode, etc., as only one half ALD cycle, without any counter reaction with another precursor, was used. Nevertheless, this approach, further entitled modified $A L D$ approach in this work, was sufficient to achieve the desired surface modification of PCM with (-)- $\alpha$-pinene. The reason for the $\mathrm{Al}_{2} \mathrm{O}_{3}$ pre-coating of PCM (using a true ALD process, i.e. cycling $\mathrm{Al}$ and $\mathrm{O}$ precursors in the traditional ALD self-saturation mode) was to sensitize the PCM surface for the imprinting with the template chiral molecule. The intact polycarbonate membrane (PCM1), the membrane imprinted with (-)- $\alpha$-pinene (PCM2) and the membrane pre-coated with $\mathrm{Al}_{2} \mathrm{O}_{3}$ and then imprinted with (-)- $\alpha$-pinene (PCM3) were evaluated, if they exhibited a different sorption capacity of $(-)$ - $\alpha$-pinene, $(+)$ - $\alpha$-pinene and their racemic mixture using a very sensitive gas sorption analyzer.

\section{Experimental}

Materials: Polycarbonate microfiltration membranes (PCM) with pore size $0.1 \mu \mathrm{m}$, (Cat. No. VCTP14250) were supplied from Millipore Ltd. USA. (1R)-(+)- $\alpha$-pinene (purity $\geq 99 \%$, optical purity ee: $97 \%$ ) and (1S)-(-)- $\alpha$-pinene (purity $\geq 99 \%$, optical purity ee: $97 \%$ ) were purchased 
from Sigma - Aldrich. Trimethylaluminum (TMA, elec. grade, 99.999+ \%) was supplied from Strem.

Atomic layer deposition technique: The chiral templating with (1S)-(-)- $\alpha$-pinene on the PCM was carried out via modified atomic layer deposition (ALD) approach, applying 25 cycles of (1S)-(-)$\alpha$-pinene (purity $\geq 99 \%$, optical purity: $97 \%$ ) as the pinene molecule (but without any ALD counter-reaction, as already explained) and commercial ALD tool (Beneq TFS-200). All processes were carried out at a temperature of $90{ }^{\circ} \mathrm{C}$ using $\mathrm{N}_{2}(99.9999 \%)$ as carrier gas at a flow rate of 400 standard cubic centimeters per minute (sccm). Under these conditions, one ALD cycle was defined by the following sequence: pinene pulse (5 s) - $\mathrm{N}_{2}$ purge (45 s).

ALD was also employed for the deposition of $\mathrm{Al}_{2} \mathrm{O}_{3}$ within PCMs. Trimethylaluminum (TMA) and deionized water (18 $\mathrm{M} \Omega$ ) were used as aluminum and oxygen precursors, respectively. All processes were carried out at a temperature of $120^{\circ} \mathrm{C}$ using $\mathrm{N}_{2}(99.9999 \%)$ as carrier gas at a flow rate of 400 standard cubic centimeters per minute (sccm). $\mathrm{Al}_{2} \mathrm{O}_{3}$ deposition was carried out running 50 ALD cycles. Under these deposition conditions, one growth ALD cycle was defined by the following sequence: TMA pulse (2 s)- $\mathrm{N}_{2}$ purge (20 s)- $\mathrm{H}_{2} \mathrm{O}$ pulse (2 s)- $\mathrm{N}_{2}$ purge (30 s). Afterwards, the same ALD process using (1S)-(-)- $\alpha$-pinene as described above was applied also to $\mathrm{Al}_{2} \mathrm{O}_{3}$ coated PCMs. Samples before and after ALD were characterized by a filed-emission scanning electron microscope (SEM, JEOL, JSM 7800F). Cross-sectional views were obtained by cutting the PCMs using ordinary scissors.

$\alpha$-pinene sorption analysis: Sorption of enantiomerically pure $(+)-\alpha$-pinene, enantiomerically pure (-)- $\alpha$-pinene, both molecules depicted in Figure 1, and their racemic mixture into three type of PCM was measured and the corresponding results are presented in following figures. 


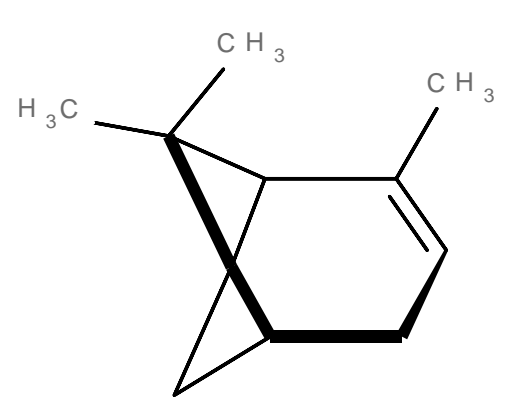

$(+)-\alpha-$ pinene

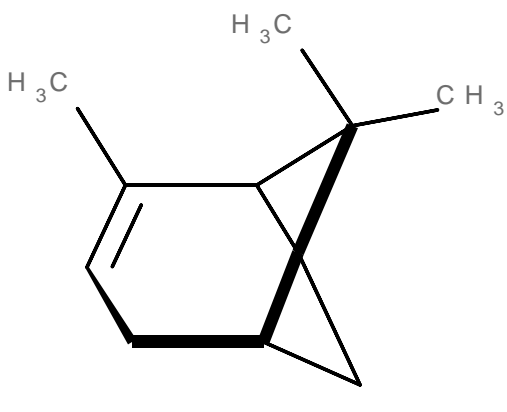

(-)-a-pinene

Figure 1. Structural formula of (+)- $\alpha$-pinene and (-)- $\alpha$-pinene

PCM1 is a track-etched polycarbonate membrane. The pore shape is cylindrical with a diameter of $100 \mathrm{~nm}$. The pores are straight and pass through the entire thickness of the membrane. The porosity of the membrane is in the range of 5 to $20 \%$ (as the manufacturer declares).

The membrane thickness was $29 \mu \mathrm{m}$.

PCM2 was the PCM 1 with the (-)- $\alpha$-pinene templating performed by modified ALD approach, the membrane thickness was $31 \mu \mathrm{m}$.

PCM3 was the PCM 1 with the $\mathrm{Al}_{2} \mathrm{O}_{3}$ layer and subsequent (-)- $\alpha$-pinene templating, both performed by ALD technique, the membrane thickness was $30 \mu \mathrm{m}$.

Each membrane sample was weighed several times after insertion into the sorption balance. The sample mass was recorded. Prior to the isothermal measurement, the membrane sample was exposed to vacuum to remove all adsorbed species, mainly water and $\mathrm{CO}_{2}$. When constant weight was reached, the dry mass was recorded. The weight loss of the membrane samples depended on relative humidity of air and ranged between 0.5 and $1.1 \mathrm{wt} . \%$. 
Saturated vapor pressure of $\alpha$-pinene at $30{ }^{\circ} \mathrm{C}$ was set to a value $7.9 \mathrm{mbar}\left(\mathrm{p}_{0}\right)$. This value was calculated according to Hawkins and Armstrong ${ }^{35}$ and also according Nelson and Chickos. ${ }^{36}$ The sorption was carried out at lower pressures to prevent condensation of $\alpha$-pinene.

Enantiomerically pure $(+)-\alpha$-pinene, enantiomerically pure $(-)$ - $\alpha$-pinene and their racemic mixture were analyzed before their use to determine the content of impurities or pinene oxidation products. A Clarus 680 gas chromatograph and a Clarus SQ8T mass spectrometer (PerkinElmer) were used for analysis. It was found that $(+)-\alpha$-pinene, $(-)-\alpha$-pinene and their racemic mixture contained oxidation products such as $\alpha$-pinene epoxide and 2-Pinen-4-ol (verbenol) in a total amount less than 1 wt. \%.

The $\alpha$-pinene sorption isotherms were determined by a gravimetric method using a dynamic sorption analyzer IGA-003 (Hiden Isochema, England). The isothermal static vapor sorption procedure was applied for the determination of static vapor sorption isotherms where the source of $\alpha$-pinene vapor was liquid $\alpha$-pinene added to an IGA reservoir. ${ }^{37,38}$ The weight of the sample was measured with an accuracy of $0.1 \mu \mathrm{g}$.

Each corresponding PCM sample was loaded into a microbalance, weighed, and evacuated until constant weight was reached. It usually took 3 days. The dry mass of the sample was then determined. The membrane sample was equilibrated to the temperature of $30{ }^{\circ} \mathrm{C}$. In the first sorption run, the pressure (p) of $\alpha$-pinene vapor was gradually increased in five steps $(0,1,2,3,4$, 5 mbar). After reaching the equilibrium weight of the sample for a given pressure, which took 180 minutes, the pressure was increased to the next value until the pressure approached $95 \%$ of the saturated $\alpha$-pinene vapor pressure. The microbalance recorded the weight change of the membrane sample. Then the pressure of $\alpha$-pinene vapor was gradually decreased in 180-min steps until the zero value was reached (the first desorption run). The second, third and fourth sorption and 
desorption runs were carried out in the same manner. The amount of adsorbed $\alpha$-pinene was related to the mass of the dry membrane sample. The sorption and desorption isotherms of pure $(+)-\alpha-$ pinene, pure (-)- $\alpha$-pinene and their racemic mixture (1:1) in the PCM were determined.

The samples before and after $\alpha$-pinene sorption were characterized by an ultra-high-resolution SEM (MAIA3, Triglav ${ }^{\mathrm{TM}}$, TESCAN).

Results and Discussion

All types of membranes used in this work were first analyzed by means of SEM, as shown in Figure 2 and 3. The average pore diameter of all membranes in this study was calculated from statistical sets ranging from 70 to 185 pores at different magnifications.

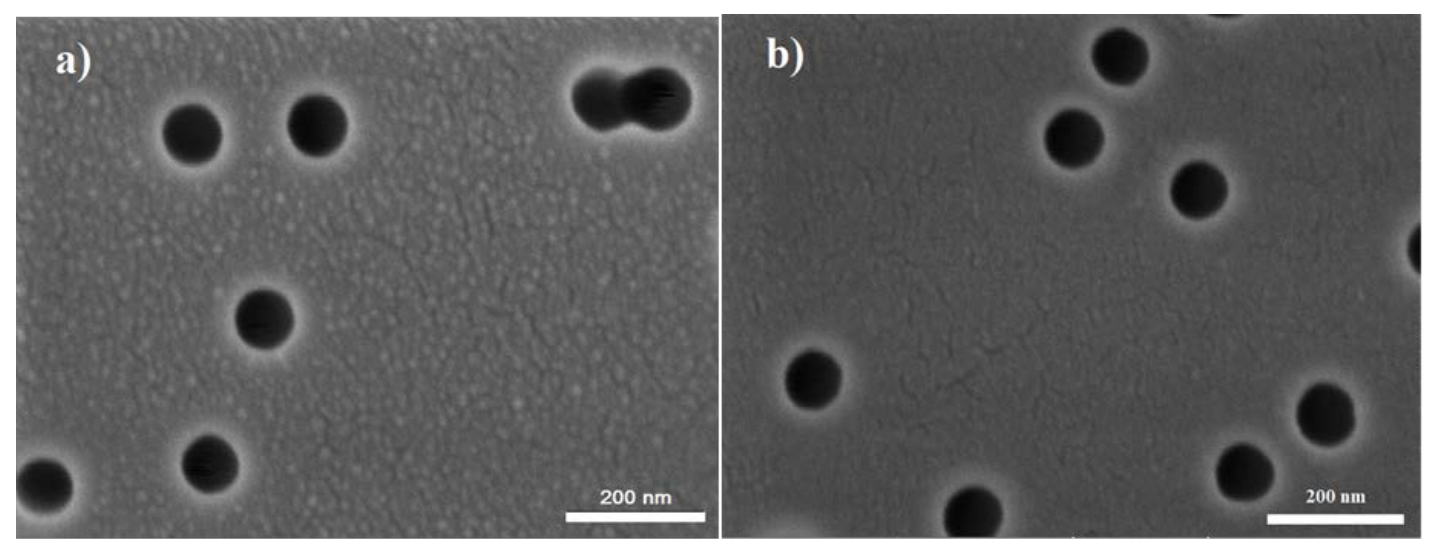

Figure 2. SEM a) top-view and b) bottom-view images of the PCM 1 (PC blank).

The thickness of all membranes was measured using a Mitutoyo digimatic micrometer. The average thickness was always calculated from 10 values (Table 1). The pore diameter of the PCM1 found by our analysis was $99.83 \pm 3.50 \mathrm{~nm}$ on one side and $100.09 \pm 4.5 \mathrm{~nm}$ on the other side of membrane (Table 2), which is in accordance with the manufacturer's stated values (100 nm). 


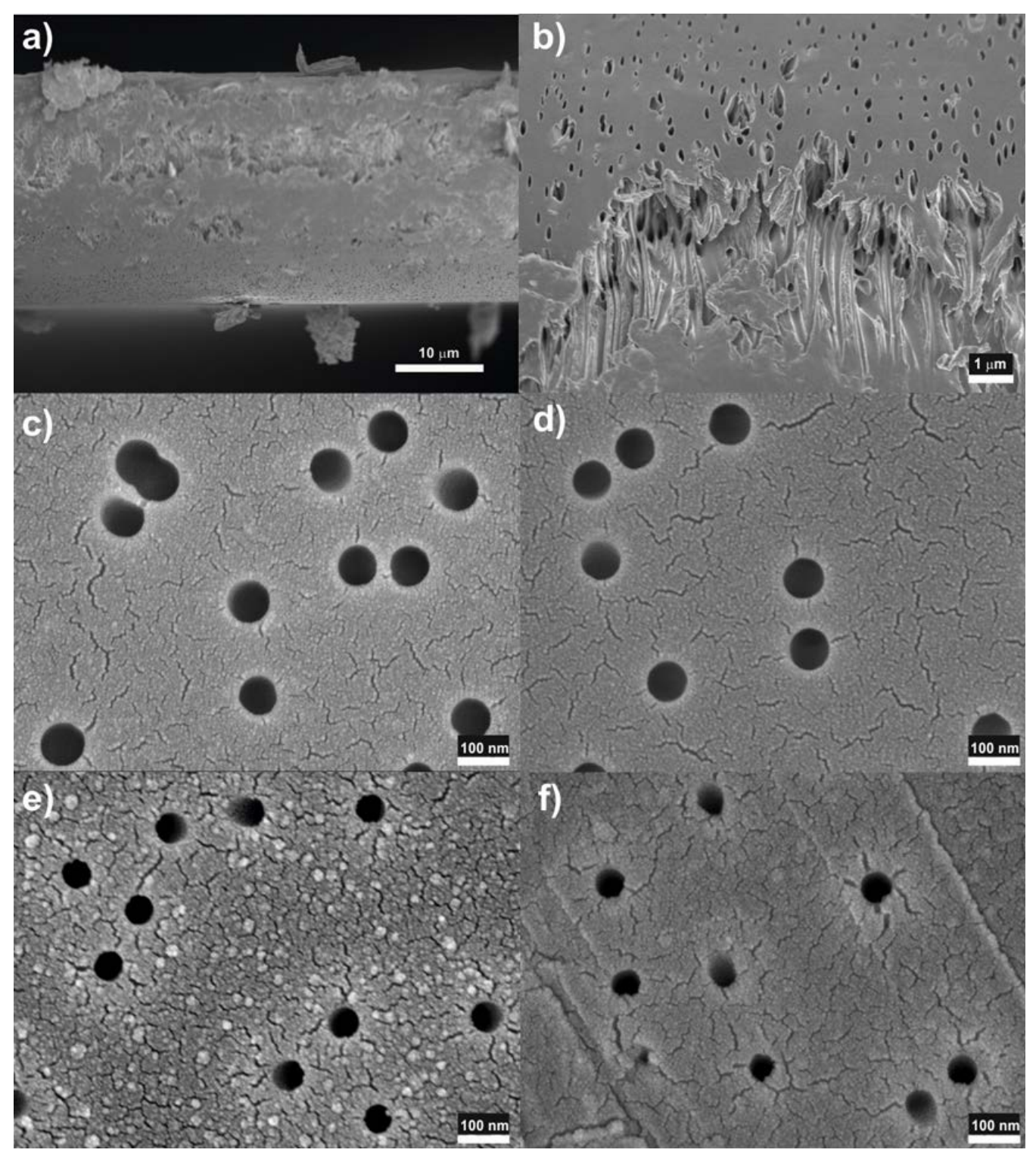

Figure 3. SEM images of: (a, b) cross-sectional views of the blank PCM (PCM1), (c-d) top-view and bottom-view images of the PCM coated with (-)- $\alpha$-pinene (PCM2), (e, f) top-view and bottomview images of the PCM coated with $\mathrm{Al}_{2} \mathrm{O}_{3}$ and (-)- $\alpha$-pinene (PCM3). A reduction of the pore diameter after $\mathrm{Al}_{2} \mathrm{O}_{3}$ ALD is clearly visible. 
Table 1. Thickness changes of PCM1, PCM2 and PCM3 before and after sorption-desorption of $\alpha$-pinene.

\begin{tabular}{|c|c|c|c|}
\hline Membrane & Conditions & Sorption & $\begin{array}{l}\text { Membrane thickness } \\
\qquad[\mu \mathrm{m}]\end{array}$ \\
\hline \multirow{4}{*}{ PCM1 blank } & Before sorption experiment & - & $29.22 \pm 1.69$ \\
\hline & \multirow{3}{*}{$\begin{array}{l}\text { After sorption-desorption } \\
\text { experiment }\end{array}$} & $(-)$ - $\alpha$-pinene & $30.45 \pm 1.88$ \\
\hline & & $(+)$ - $\alpha$-pinene & $29.60 \pm 1.36$ \\
\hline & & $\begin{array}{l}\text { Racemic } \\
\text { mixture }\end{array}$ & $30.67 \pm 2.09$ \\
\hline \multirow{4}{*}{$\begin{array}{l}\text { PCM2 } \\
\text { ALD (-)- } \alpha \text {-pinene }\end{array}$} & Before sorption experiment & - & $31.33 \pm 0.94$ \\
\hline & \multirow{3}{*}{$\begin{array}{l}\text { After sorption-desorption } \\
\text { experiment }\end{array}$} & (-)- $\alpha$-pinene & $32.09 \pm 1.68$ \\
\hline & & $(+)$ - $\alpha$-pinene & $32.00 \pm 1.51$ \\
\hline & & $\begin{array}{l}\text { Racemic } \\
\text { mixture }\end{array}$ & $31.58 \pm 1.89$ \\
\hline \multirow{4}{*}{$\begin{array}{l}\text { PCM3 } \\
\mathrm{ALD} \mathrm{Al}_{2} \mathrm{O}_{3} \\
\mathrm{ALD}(-)-\alpha \text {-pinene }\end{array}$} & Before sorption experiment & - & $29.63 \pm 0.70$ \\
\hline & \multirow{3}{*}{$\begin{array}{l}\text { After sorption-desorption } \\
\text { experiment }\end{array}$} & (-)- $\alpha$-pinene & $30.13 \pm 1.76$ \\
\hline & & $(+)$ - $\alpha$-pinene & $30.07 \pm 1.71$ \\
\hline & & $\begin{array}{l}\text { Racemic } \\
\text { mixture }\end{array}$ & $30.00 \pm 1.29$ \\
\hline
\end{tabular}

The thickness of PCM1 was approximately $29.22 \pm 1.69 \mu \mathrm{m}$ (Figure 3a, b and Table 1). After the ALD pinene templating process (carried out at the temperature of $90{ }^{\circ} \mathrm{C}$ ), the PCM2 underwent visible changes. The thickness of PCM2 was $31.33 \pm 0.94 \mu \mathrm{m}$. Our morphological analysis showed that the pore diameter was reduced to $79.20 \pm 5.13 \mathrm{~nm}$ on one side and $77.61 \pm 6.03 \mathrm{~nm}$ on the other side of the membrane, that is, the pore diameter of PCM2 was reduced approximately to 78.5 $\%$ of the original membrane pore size on both sides of the membrane. 
Table 2. Pore diameter changes before and after the sorption-desorption experiment of $\alpha$-pinene

\begin{tabular}{|c|c|c|c|}
\hline \multirow[t]{2}{*}{ Membrane } & \multirow[t]{2}{*}{ Conditions } & \multicolumn{2}{|c|}{$\begin{array}{c}\text { Pore diameter } \\
{[\mathrm{nm}]}\end{array}$} \\
\hline & & Mem. side 1 & Mem. side 2 \\
\hline \multirow[b]{2}{*}{ PCM1 blank } & Before sorption experiment & $99.83 \pm 3.50$ & $100.09 \pm 4.50$ \\
\hline & $\begin{array}{l}\text { After sorption-desorption } \\
\text { of }(-) \text { - } \alpha \text {-pinene }\end{array}$ & $78.51 \pm 6.38$ & $81.86 \pm 3.98$ \\
\hline \multirow{2}{*}{$\begin{array}{l}\text { PCM2 } \\
\text { ALD (-)- } \alpha \text {-pinene }\end{array}$} & Before sorption experiment & $77.61 \pm 6.03$ & $79.20 \pm 5.13$ \\
\hline & $\begin{array}{l}\text { After sorption-desorption } \\
\text { of }(-) \text { - } \alpha \text {-pinene }\end{array}$ & $37.88 \pm 5.94$ & $38.31 \pm 9.13$ \\
\hline \multirow{3}{*}{$\begin{array}{l}\text { PCM3 } \\
\text { ALD } \mathrm{Al}_{2} \mathrm{O}_{3} \\
\text { ALD (-)- } \alpha \text {-pinene }\end{array}$} & Before sorption experiment & $72.53 \pm 4.63$ & $72.87 \pm 3.13$ \\
\hline & $\begin{array}{l}\text { After sorption-desorption } \\
\text { of (-)- } \alpha \text {-pinene }\end{array}$ & $59.63 \pm 7.29$ & $60.47 \pm 7.12$ \\
\hline & of $(+)-\alpha$-pinene & $66.30 \pm 5.72$ & $68.83 \pm 6.91$ \\
\hline
\end{tabular}

This means that the PC expands at a higher temperature during the ALD (-)- $\alpha$-pinene templating process increasing the free volume between the PC chains and making the pinene molecules diffuse more easily into the surface layers of the pore walls and the membrane surface. This results in irreversible swelling and disruption of the surface by micro-cracks, as shown in Figure 3c, d. After ALD process of $\mathrm{Al}_{2} \mathrm{O}_{3}$ and (-)- $\alpha$-pinene templating, the membrane thickness was $29.63 \pm 0.70 \mu \mathrm{m}$ and the diameter of the pores was reduced from average of $100 \mathrm{~nm}$ to 72.53 $\pm 4.63 \mathrm{~nm}$ on one side and to $72.87 \pm 3.13 \mathrm{~nm}$ on the other side of the coated PCM3 (Table 2). The narrower pore diameter (higher swelling degree) as compared to PCM2 would indicate that ALD of $\mathrm{Al}_{2} \mathrm{O}_{3}$ took place over the entire surface of the PCM pores, which was essentially desired from 
the very beginning of the experimental design of this work. It was consistent with the uniform ALD coating results of 1D nanotubular layers using various secondary materials. ${ }^{34}$

However, ALD of $\mathrm{Al}_{2} \mathrm{O}_{3}$ had also some unwanted effect on the PCM, due to either thermal expansion of PCM during ALD of $\mathrm{Al}_{2} \mathrm{O}_{3}$ or reaction of PCM with TMA or combination of both. As a result, cracking of the PCM surface was observed and a formation of non-continuous $\mathrm{Al}_{2} \mathrm{O}_{3}$ layer was seen (Figure 3e, f). No visible effects on PMA was observed though, when PCM (without $\mathrm{Al}_{2} \mathrm{O}_{3}$ ) were heated up in air in a regular oven to the same temperature as used for the ALD process $\left(120^{\circ} \mathrm{C}\right.$, data now shown). In fact, higher mobility of PC polymer chains at this ALD process temperature, creating a larger free volume between the individual chains that contribute to the enhanced TMA diffusion in the PCM. In this case, TMA is able to penetrate the membrane surface, form $\mathrm{Al}_{2} \mathrm{O}_{3}$ aggregates beneath the membrane surface ${ }^{39}$ and also interact with PC carbonyl groups, ${ }^{40,41}$ resulting in a membrane swelling with a significant reduction in pore diameter apparent after the ALD process has been finished. Addition of 25 ALD cycles of (-)- $\alpha$-pinene at $90{ }^{\circ} \mathrm{C}$ can lead to further thermal expansion and swelling of the membrane, resulting in a larger narrowing of the pores. From these facts, it is apparent that the (-)- $\alpha$-pinene was not embedded as a multilayer, but rather retained in small amounts on the $\mathrm{Al}_{2} \mathrm{O}_{3}$ layer and in the subsurface layers of the PCM. Since pinene is not bound in the membrane by covalent bonds, most of the pinene molecules can be washed away in each nitrogen purge cycle, after which a pinene molecule imprint can remain in the $\mathrm{PC}$ or in the $\mathrm{Al}_{2} \mathrm{O}_{3}$ layer. Also, a small number of pinene molecules can remain trapped in the PC surface layers or on the $\mathrm{Al}_{2} \mathrm{O}_{3}$ layer. It should be mentioned though that the presence of ()- $\alpha$-pinene was not revealed by additional measurements, such as infrared spectroscopy, Raman spectroscopy, thermal gravimetry or X-ray photoelectron spectroscopy. The amount of pinene trapped in the PCM was below the detection limit of any of these techniques. It can be assumed 
that most of the pinene molecules were removed by nitrogen during the purging pulse and the (-)$\alpha$-pinene molecules left their imprint in the $\mathrm{Al}_{2} \mathrm{O}_{3}$ layer and in the surface layers of the PCM. Yet, the (-)- $\alpha$-pinene was present within the PCM pores after the ALD process (regardless the presence or absence of the supporting $\mathrm{Al}_{2} \mathrm{O}_{3}$ coating), as revealed by sorption experiments shown further in the text.

The sorption of enantiomerically pure $(-)-\alpha$-pinene, enantiomerically pure $(+)-\alpha-p i n e n e$ and their racemic mixture in the PCM1 was very low (Figure 4). Sorption curves of (-)- $\alpha$-pinene in the PCM1 (Figure 4a) indicated that weak interactions between PC and (-)- $\alpha$-pinene occurred mainly in the first and second run and also that (-)- $\alpha$-pinene molecules diffused into the subsurface layers of the PCM and swelled it. The sorption and desorption isotherm shape suggests that sorption of (-)- $\alpha$-pinene occurred in the pores of the PCM and the hysteresis was associated with filling and emptying pores ${ }^{42}$ and also with diffusion of the pinene molecules into the subsurface layers of PCM. It is known that synthetic polymers are able to simultaneously adsorb (on the surface) and absorb low-molecular organics substances. Small organic molecule compounds are able to penetrate into the free volume between polymer chains. Thus, they can have access to new active sorption centers. This corresponds to the gradually increasing sorption with each subsequent period (Figure 4d).

The sorption of $(+)-\alpha-$-pinene in the PCM1 is slightly lower than sorption of $(-)-\alpha$-pinene (Figure 4b). Only in the first cycle there was a sign of pore filling or dissolution of $(+)-\alpha-p i n e n e$ in the PCM. The shape of hysteresis in the first sorption run suggests that the sorption (adsorption and absorption) of (+)- $\alpha$-pinene molecules into the subsurface layers of PCM was slower and the sorption reached lower values than those of $(-)-\alpha-$ pinene molecules. This would point to that $(+)-$ 
$\alpha$-pinene molecules are less able to interact chemically with sorption sites and penetrate more slowly into the subsurface layers of PCM than (-)- $\alpha$-pinene molecules.

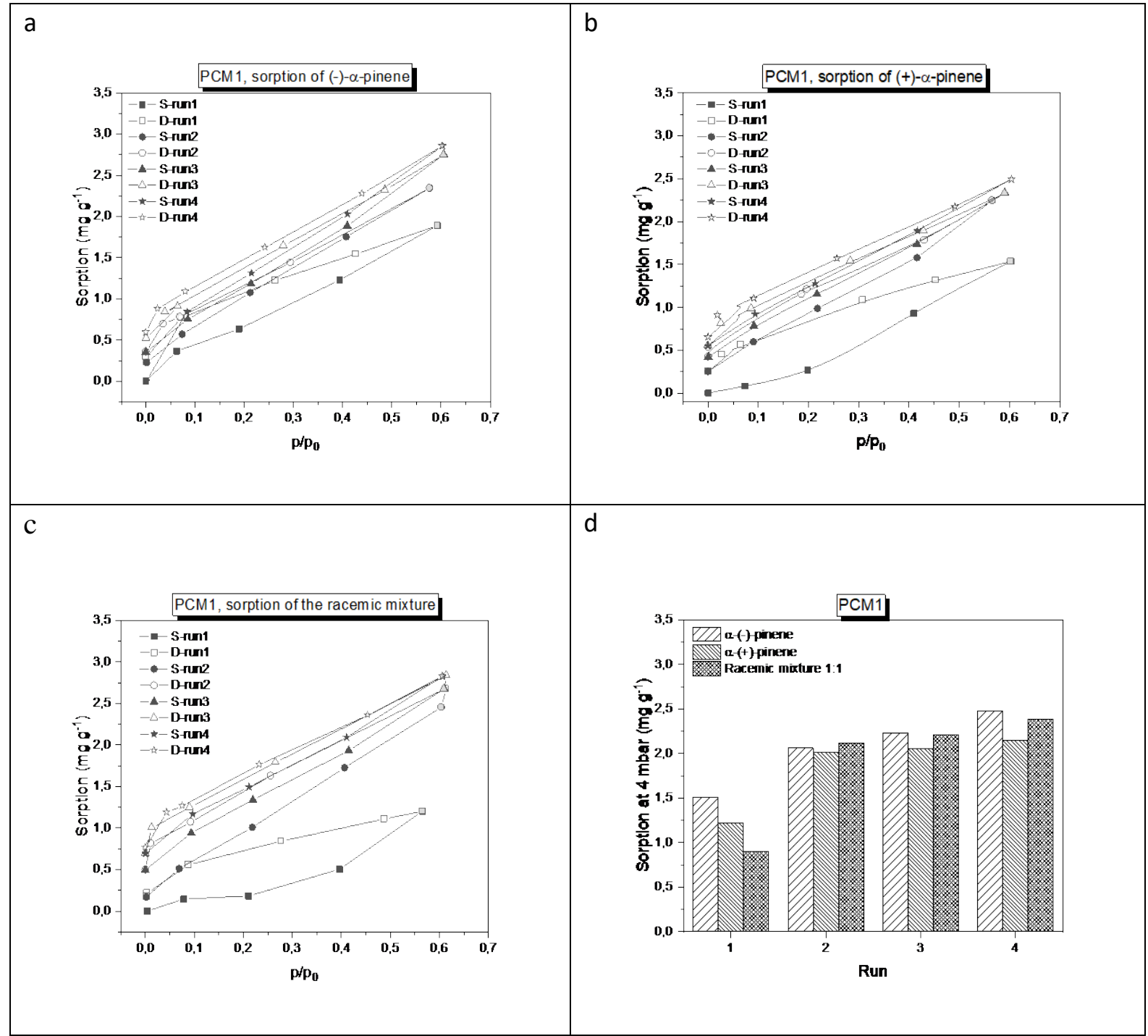

Figure 4. Sorption of (-)- $\alpha$-pinene (a), (+)- $\alpha$-pinene (b) and their racemic mixture 1:1 (c) into the PCM1. Comparison of sorption of $(-)-\alpha-$-pinene, $(+)-\alpha$-pinene and their racemic mixture into the polycarbonate blank membrane at a pressure of $4 \mathrm{mbar}=0.51 \mathrm{p} / \mathrm{p}_{0}(\mathrm{~d})$.

The course of the (+)- $\alpha$-pinene sorption curves was similar in the remaining runs (from the second to the fourth), because the PCM was probably saturated with (+)- $\alpha$-pinene at a given 
pressure. This means, the weight of the sample does not change over time because the number of adsorbed/absorbed and desorbed molecules is practically the same for a given pressure, as shown in Figure 4b, d.

The sorption of the racemic mixture (Figure 4c) reached values that are between those ones measured on pure (-)- $\alpha$-pinene and (+)- $\alpha$-pinene (Figure 4d), except for the first run. This would indicate that (-)- $\alpha$-pinene, which is 50 wt.\% present in the racemic mixture, is preferably adsorbed/absorbed. The sorption values of the racemic mixture during the second and third run were close to the sorption value of (-)- $\alpha$-pinene. However, the sorption of the racemic mixture during the fourth run was between the sorption of both enantiomers, that is, the sorption of both enantiomers reached an equilibrium value for a given vapor pressure.

The desorption isotherms show almost the same original mass at the pressure 0 mbar. Because the experiments lasted for a limited time, it was not possible to reach the initial sample weight. This would require several days or weeks of desorption at the pressure of 0 mbar to achieve complete desorption of all pinene molecules that were trapped in the deeper trenches of PCM. The desorption behavior of the PCM and pinene molecules indicated that the original membrane weight would be reached after long desorption times. Therefore, it can be concluded that there was no chemical reaction of the pinene molecules with the polycarbonate. Thus, the sorption process (adsorption or absorption) was assumed to be completely reversible.

The sorption results were supported by a morphological analysis, shown in Figure 5. The PCM1 was analyzed before and after four sorption and desorption runs of (-)- $\alpha$-pinene. PCM1 showed significant changes after pinene sorption and desorption experiment. The thickness of PCM1 before the sorption experiment was $29.22 \pm 1.69 \mu \mathrm{m}$ (Table 1), the surface of PCM1 was 
smooth and the pore diameter was $99.83 \pm 3.50 \mathrm{~nm}$ on one side of the membrane and $100.09 \pm 4.5$ nm on the other side (Figure 5a, Table 2). The surface of the PCM1 exposed to the repeated sorption and desorption of (-)- $\alpha$-pinene became rough, the membrane thickness slightly increased to $30.45 \pm 1.88 \mu \mathrm{m}$ and the pore diameter decreased to $78.51 \pm 6.38 \mathrm{~nm}$ on one side of membrane and $81.86 \pm 3.98$ on the other side (Figure $5 b$, Table 2 ). The results indicate that the PCM polymer chains are rearranged and the free volume between the chains increases with long-term exposure of the pinene molecules at the temperature of $30^{\circ} \mathrm{C}$. This results in irreversible swelling of the PC and access to the sorption centers during repeated sorption experiments. The pore diameter of PCM1 after repeated sorption-desorption of (-)- $\alpha$-pinene, $(+)$ - $\alpha$-pinene and their racemic mixture did not show any significant differences.

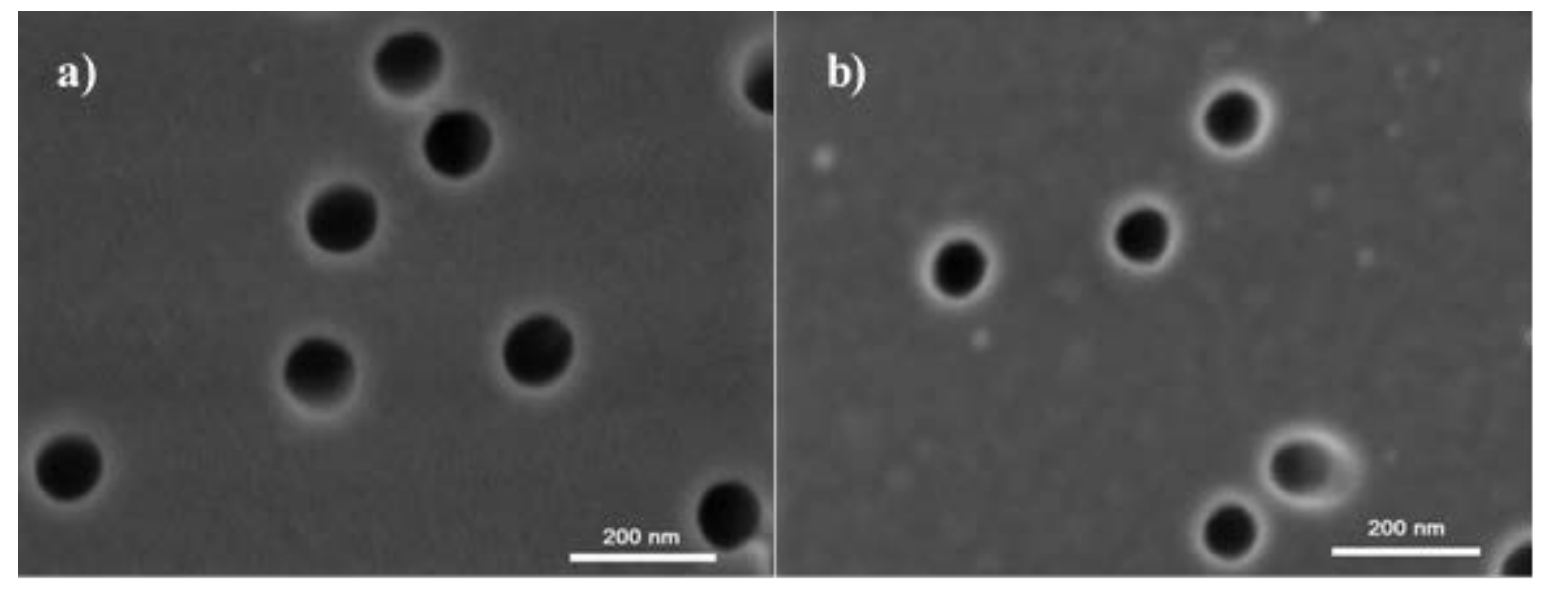

Figure 5. SEM images of the PCM1 before (a) and after repeated sorption and desorption of (-)$\alpha$-pinene (b)

The total sorption of $(-)$ - $\alpha$-pinene, $(+)$ - $\alpha$-pinene and their racemic mixture in the PCM2 exposed to (-)- $\alpha$-pinene using the modified ALD approach is higher in comparison with the PCM1 (Figure 6). In this case, the PCM2 was previously exposed to 25 cycles of (-)- $\alpha$-pinene application by the ALD process, which was carried out at $90{ }^{\circ} \mathrm{C}$. According to the Maxwell-Boltzmann distribution, the most likely pinene molecules speed is $210.5 \mathrm{~m} \mathrm{~s}^{-1}$ at given conditions. If the pore 
diameter is lower than $100 \mathrm{~nm}$, it can be assumed that the pinene molecules penetrate the pores by Knudsen diffusion, that is, the pinene molecules more often collide with the pore walls than with each other.

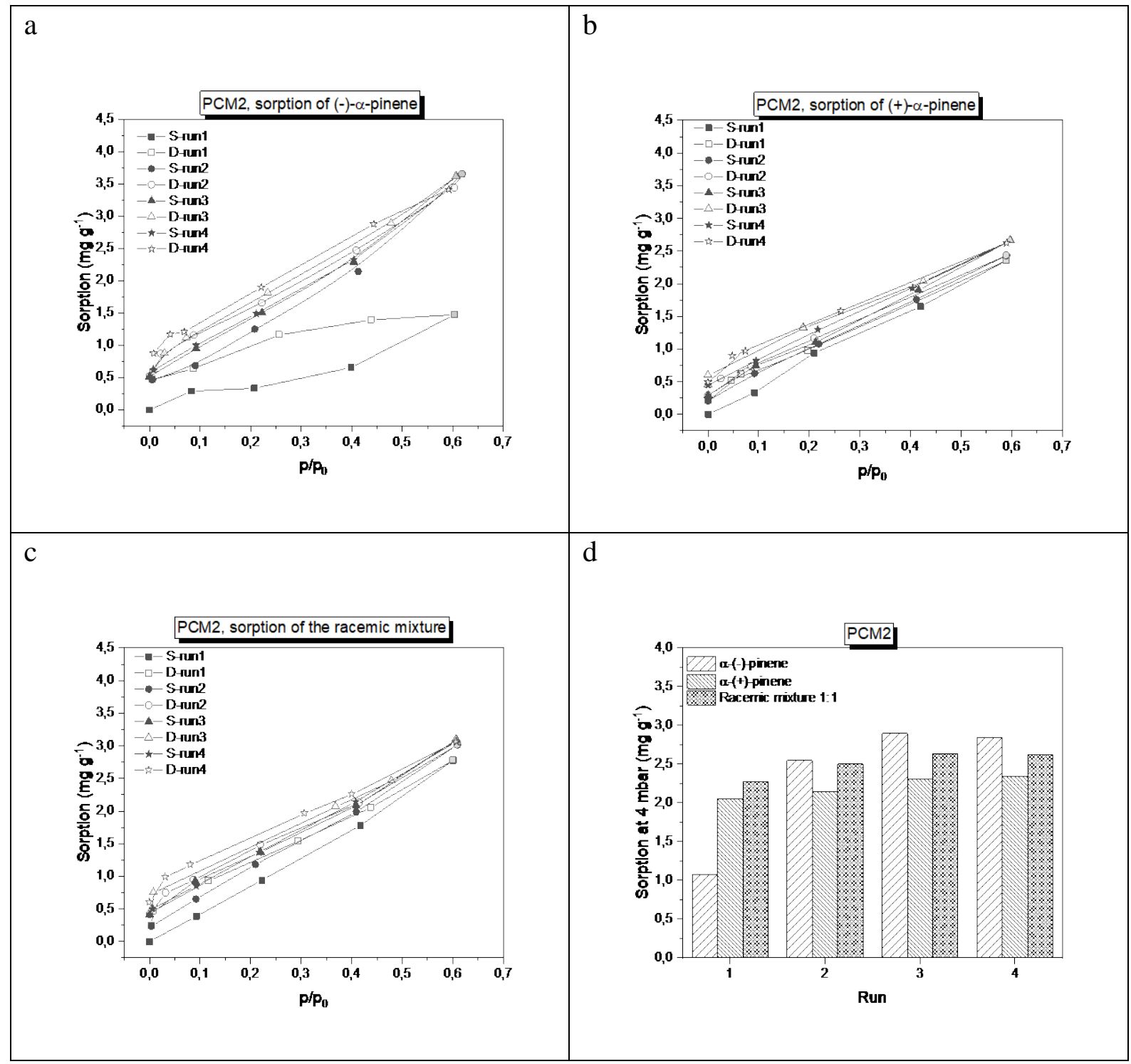

Figure 6. Sorption of (-)- $\alpha$-pinene (a), (+)- $\alpha$-pinene (b) and their racemic mixture 1:1 (c) into the PCM2. Comparison of (-)- $\alpha$-pinene, $(+)-\alpha-$ pinene sorption and racemic mixture sorption in the PCM with a (-)- $\alpha$-pinene layer at $4 \mathrm{mbar}=0.51 \mathrm{p} / \mathrm{p}_{0}(\mathrm{~d})$. 
Theoretically, the PC chains are much more mobile at $90{ }^{\circ} \mathrm{C}$ and the membrane surface and inner walls of pores can interact with the pinene molecules which penetrate more easily into the subsurface layers, rearranged PC chains and so the (-)- $\alpha$-pinene molecules can be trapped or can leave their imprint in the swollen PCM. ${ }^{43}$

The sorption of (-)- $\alpha$-pinene, $(+)-\alpha$-pinene and their racemic mixture into the PCM2 was carried out at $30{ }^{\circ} \mathrm{C}$. The $\alpha$-pinene sorption was higher compared to PCM1 and sorption and desorption process was completely reversible. The course of (-)- $\alpha$-pinene sorption into the PCM2 was similar to the PCM1 and showed clearly visible hysteresis in the first sorption run. Hysteresis and lower sorption in the first run may be due to the filling of imprinted sites in the swollen subsurface layers of the PCM and due to the occupation of some suitable sorption sites with the ()- $\alpha$-pinene molecules templated by the modified ALD approach. ${ }^{44-46}$ The sorption of $(+)$ - $\alpha$-pinene into the PCM2 did not show hysteresis in the first sorption run and the adsorbed/absorbed amount of pinene was approximately the same, as in the PCM1 case. This suggests that: i) (+)- $\alpha$-pinene was adsorbed/absorbed and this process occurred predominantly on the membrane surface and at the sterically accessible sorption sites created after the swelling of the PC during ALD (-)- $\alpha$-pinene process; ii) the PCM is fully saturated with (+)- $\alpha$-pinene under given conditions. The sorption of racemic mixture into PCM2 showed slight hysteresis in the first sorption run, which is probably due to the presence (-)- $\alpha$-pinene in the mixture. This sorption behavior suggests that $(-)$ - $\alpha$-pinene templated by the modified ALD approach at $90{ }^{\circ} \mathrm{C}$ diffused into the subsurface layer of PC and created new sites suitable for (-)- $\alpha$-pinene sorption, whereas these sites were sterically unavailable for (+)- $\alpha$-pinene sorption.

Morphological analysis of the PCM2 before and after (-)- $\alpha$-pinene sorption showed (Figure 7) that the (-)- $\alpha$-pinene molecules applied by the modified ALD approach at $90{ }^{\circ} \mathrm{C}$ caused a swelling 
of the inner pore walls and the membrane surface, thereby allowing the higher resulting pinene sorption. The pore diameter after (-)- $\alpha$-pinene ALD was $77.61 \pm 6.03 \mathrm{~nm}$ on one side and $79.20 \pm$ $5.13 \mathrm{~nm}$ on the other side of the PCM (Table 2). The thickness of the PCM2 before the sorption experiment was $31.33 \pm 0.94 \mu \mathrm{m}$. Compared to the original PCM1, the thickness increased by almost $7 \%$ (Table 1).

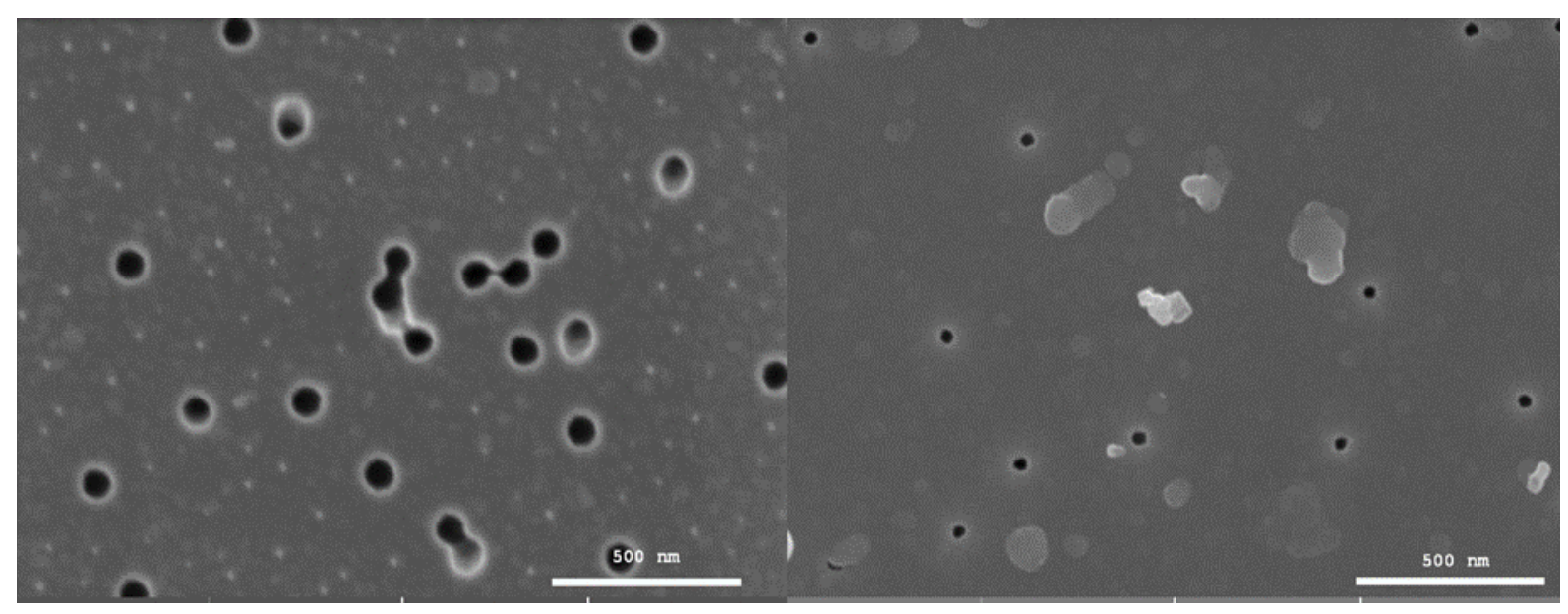

Figure 7. SEM images of the PCM2 before (a) and after repeated sorption of (-)- $\alpha$-pinene (b). The pore diameter after repeated sorption of (-)- $\alpha$-pinene was $37.88 \pm 5.94 \mathrm{~nm}$ on one side and $38.31 \pm 9.13$ on the other side (Table 2).

These results demonstrate that (-)- $\alpha$-pinene molecules are capable of penetrating deep PCM layers and with long-term exposure even at lower temperature, in our case $30{ }^{\circ} \mathrm{C}$, the $\alpha$-pinene is able to significantly swell the PCM. The narrowing of the pores during the templating of pinene molecules by the modified ALD approach can thus be attributed to two factors, namely the already mentioned thermal expansion of PC at $90{ }^{\circ} \mathrm{C}$, and the swelling of PCM caused by adsorption and absorption of pinene molecules.

Sorption of (-)- $\alpha$-pinene in the PCM3 reached approximately the same value as for PCM1 and PCM2, but hysteresis was missing in the first run (Figure 8a). This sorption behavior suggests that 
the inner pore walls and the membrane surface were covered with an $\mathrm{Al}_{2} \mathrm{O}_{3}$ layer that limited the penetration of the (-)- $\alpha$-pinene molecules into the subsurface PC layers.

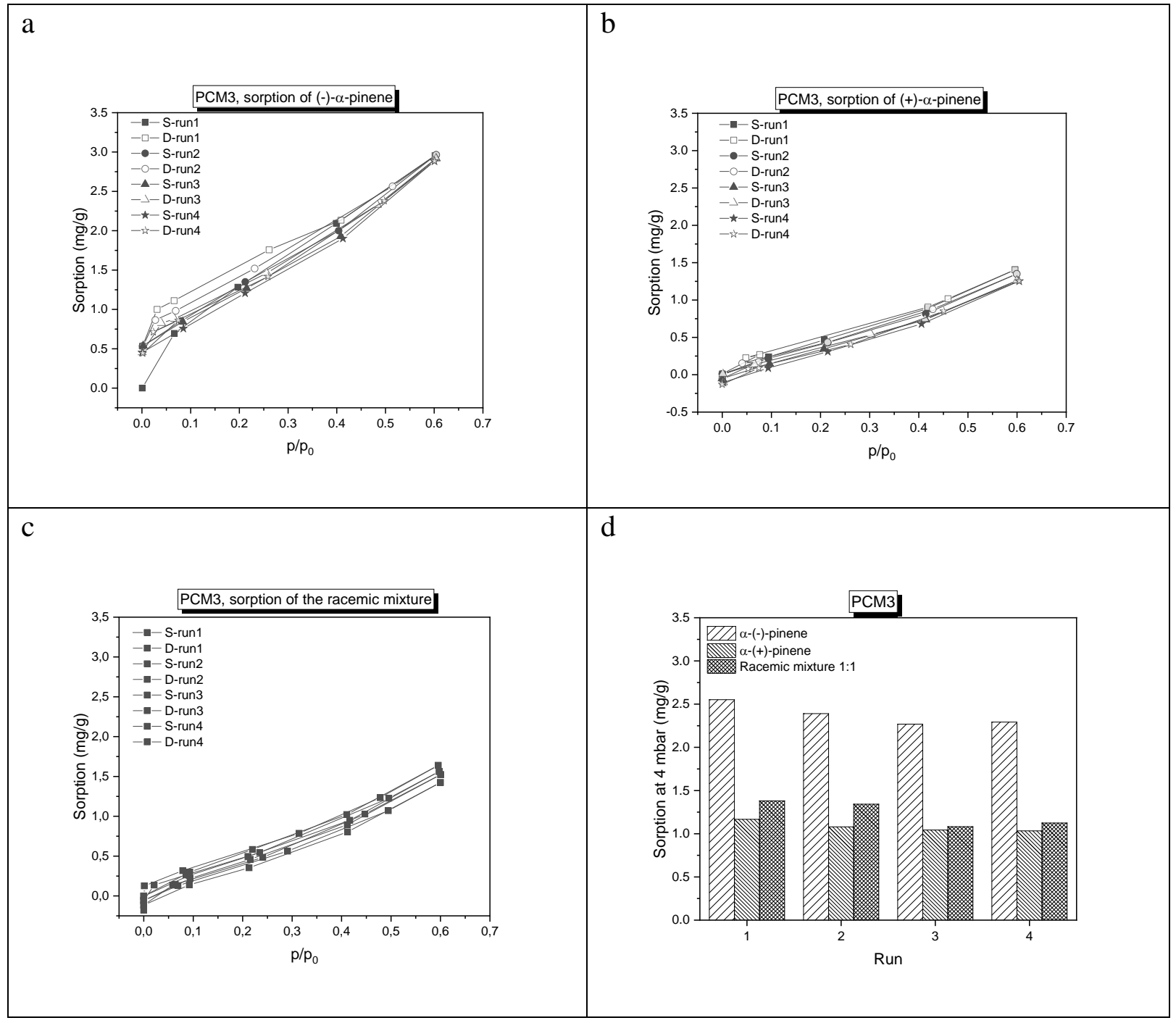

Figure 8. Sorption of (-)- $\alpha$-pinene (a), (+)- $\alpha$-pinene (b) and their racemic mixture 1:1 (c) into the PCM3. Comparison of (-)- $\alpha$-pinene, $(+)-\alpha$-pinene sorption and racemic mixture sorption in a PCM with the $\mathrm{ALD} \mathrm{Al}_{2} \mathrm{O}_{3}$ and (-)- $\alpha$-pinene layer at $4 \mathrm{mbar}=0.51 \mathrm{p} / \mathrm{p}_{0}(\mathrm{~d})$.

The following templating of (-)- $\alpha$-pinene molecules using the modified ALD approach at 90 ${ }^{\circ} \mathrm{C}$ could create suitable sorption sites on the surface as well as inside the $\mathrm{Al}_{2} \mathrm{O}_{3}$ layer and inside 
of sublayers of PCM and thus allow higher sorption of the (-)- $\alpha$-pinene. This was confirmed by the results of morphological analysis (Figure 9) which showed that repeated sorption-desorption of (-)- $\alpha$-pinene reduced the pore diameter of PCM3 from approximately $72 \mathrm{~nm}$ to $59.63 \pm 7.29$ nm on one side of the membrane and $60.47 \pm 7.12 \mathrm{~nm}$ on the other side (Table 2).

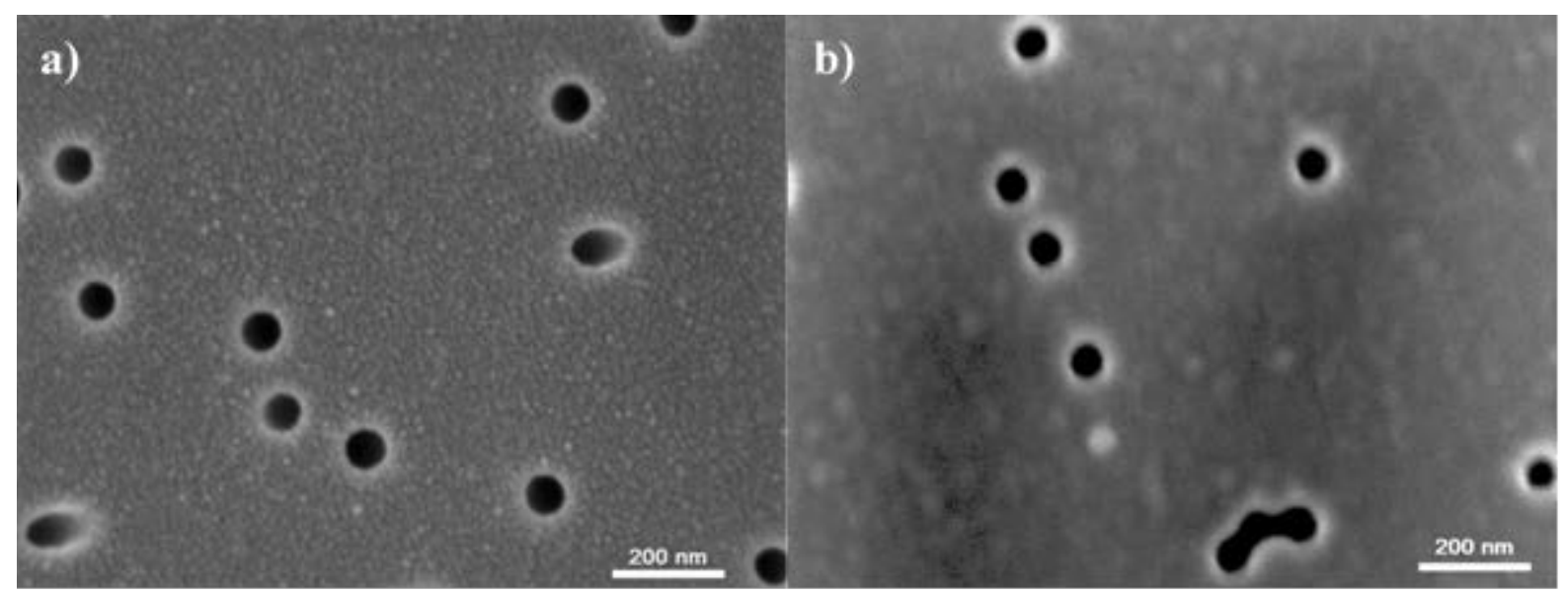

Figure 9. SEM images of the PCM3 membrane before (a) and after repeated sorption of (-)- $\alpha-$ pinene (b).

In comparison with PCM1 and PCM2, sorption of (+)- $\alpha$-pinene into the PCM3 reached only 55 rel.\% at pressure of 4 mbar. This phenomenon can be caused both by the decreasing size of the sorption surface as a result of deposition of $\mathrm{Al}_{2} \mathrm{O}_{3}$ and by the limited diffusion of $(+)$ - $\alpha$-pinene through the $\mathrm{Al}_{2} \mathrm{O}_{3}$ layer to the PCM surface. This was confirmed by the results of morphological analysis (Table 2), which showed that the repeated sorption-desorption of $(+)-\alpha$-pinene reduced the pore diameter of PCM 3 from approximately $72 \mathrm{~nm}$ to $66.30 \pm 5.72 \mathrm{~nm}$ on one side of the membrane and $68.83 \pm 6.91 \mathrm{~nm}$ on the other side. This would indicate that $(+)$ - $\alpha$-pinene dissolved less in the membrane and was mostly adsorbed and absorbed within the $\mathrm{Al}_{2} \mathrm{O}_{3}$ surface layer and free volume of the membrane. Sorption of the racemic mixture into the PCM3 at pressure of 4 mbar reached only 50 rel.\% of the sorption obtained on the PCM1 and PCM2. The changes in PCM3 thickness after application of $\mathrm{Al}_{2} \mathrm{O}_{3}$ and (-)- $\alpha$-pinene by ALD were not as large as they 
were with PCM2 (Table 1). This confirms that the presence of $\mathrm{Al}_{2} \mathrm{O}_{3}$ layer limits the penetration of pinene molecules into the PC and therefore the swelling of the PCM3 is less pronounced than in the case of PCM2.

The ideal sorption selectivity of PCM3 determined from the adsorbed/absorbed amount of the individual enantiomers (-)- $\alpha$-pinene/(+)- $\alpha$-pinene was approximately 2.2. The sorption selectivity was not confirmed by measurement of the sorption of the racemate into PCM3. To clarify this behavior, the diffusion coefficients of the individual enantiomers and racemate were calculated according to the equation (1): ${ }^{47}$

$\frac{M_{t}}{M_{\infty}}=1-\sum_{n=0}^{\infty} \frac{8}{[(2 n+1) \pi]^{2}} \exp \left[\frac{-D(2 n+1)^{2} \pi^{2}\left(t-t_{0}\right)}{h^{2}}\right]$

where $M_{t}$ is the amount species at time $t-t_{0}, M_{\infty}$ is the total amount of species that has diffused into membrane after infinity time, $D$ is the diffusivity and $h$ is the membrane thickness.

The results of kinetic measurements of weight of membranes in time during the sorption of $\alpha$ pinene racemic mixture and individual enantiomers are presented in Supporting Information file as Figures S1-S3. The calculated diffusion coefficients of individual enantiomers and the racemic mixture are given in Table 3 and showed that (-)- $\alpha$-pinene had a lower kinetic parameter (diffusion coefficient) than $(+)-\alpha$-pinene. This suggests that $(-)-\alpha$-pinene has a higher affinity to the membrane and is dissolved more in it compared to $(+)-\alpha$-pinene. This thermodynamic process is much slower than the kinetic one, represented by the diffusion coefficient. In this case, the $(+)-\alpha-$ pinene contained in the racemic mixture, which has a higher diffusion coefficient than the (-)- $\alpha-$ pinene, penetrated the free volume of the membrane very quickly, thus probably preventing an access of (-)- $\alpha$-pinene molecules to the sorption centers. This results in a lower sorption of the 
racemic mixture, which was confirmed by the value of the diffusion coefficient of the racemic mixture, which was very close to the value of the diffusion coefficient of (+)- $\alpha$-pinene.

Table 3. Values of diffusion coefficients of $(-)-\alpha$-pinene, $(+)-\alpha$-pinene and their racemic mixture adsorbed/absorbed into PCM3

\begin{tabular}{lc}
\hline Adsorbed/absorbed substance & $\begin{array}{c}\text { Diffusion coefficient } \times 10^{13} \\
\left(\mathrm{~m}^{2} \mathrm{~s}^{-1}\right)\end{array}$ \\
\hline$(-)$ - $\alpha$-pinene & $6.92 \pm 0.34$ \\
$(+)-\alpha-$ pinene & $7.78 \pm 0.37$ \\
Racemic mixture & $8.01 \pm 0.46$ \\
\hline
\end{tabular}

Interestingly, the sorption of (+)- $\alpha$-pinene and the racemic mixture in the PCM3 reduced the weight of the samples below the initial value during desorption runs (Figure 8b, c). One possible explanation for this phenomenon is that $(+)-\alpha$-pinene molecules have an affinity for $(-)-\alpha$-pinene molecules and can release (-)- $\alpha$-pinene molecules trapped in the $\mathrm{Al}_{2} \mathrm{O}_{3}$ layer.

Morphological analysis of the PCM3 showed (Figure 9a) that by applying 50 ALD cycles of $\mathrm{Al}_{2} \mathrm{O}_{3}$ and 25 ALD cycles of (-)- $\alpha$-pinene at $90{ }^{\circ} \mathrm{C}$ led to a reduction in pore diameter to approximately $72.5 \mathrm{~nm}$. TMA is able to penetrate the subsurface layers of the PCM and thus cause swelling and roughening of the PCM surface..$^{40,41}$ The penetration of TMA molecules into the subsurface layers of the PCM pores and subsequent hydrolysis of TMA to $\mathrm{Al}_{2} \mathrm{O}_{3}$ caused the deterioration of mechanical properties of the PCM, as it became brittle. After applying the $\mathrm{Al}_{2} \mathrm{O}_{3}$ layer, the PCM was exposed to 25 ALD cycles of (-)- $\alpha$-pinene at $90{ }^{\circ} \mathrm{C}$. The $\mathrm{Al}_{2} \mathrm{O}_{3}$ layer prepared by the ALD technique has a large number of $\mathrm{OH}$ groups on its surface, therefore the last layer can be considered as a Lewis acid. Thus, it can be assumed that interactions of $\mathrm{OH}$ groups with the ()- $\alpha$-pinene templating by the modified ALD approach can occur and interaction products can be 
formed. EDX analyses showed that the amount of $\mathrm{Al}_{2} \mathrm{O}_{3}$ on both membrane surfaces reached 2.6 and $2.8 \mathrm{wt} . \%$, respectively. The presence of $\mathrm{Al}_{2} \mathrm{O}_{3}$ was also proved on the fracture surface but the exact amount could not be determined due to the fracture surface character and resulting significant electron scattering during the EDX analysis.

However, it can be stated that the inner walls of the pores were covered with $\mathrm{Al}_{2} \mathrm{O}_{3}$ as shown in Figure 10. PCM1 pores had smooth walls, while PCM3 pores had a rough surface and were narrower.

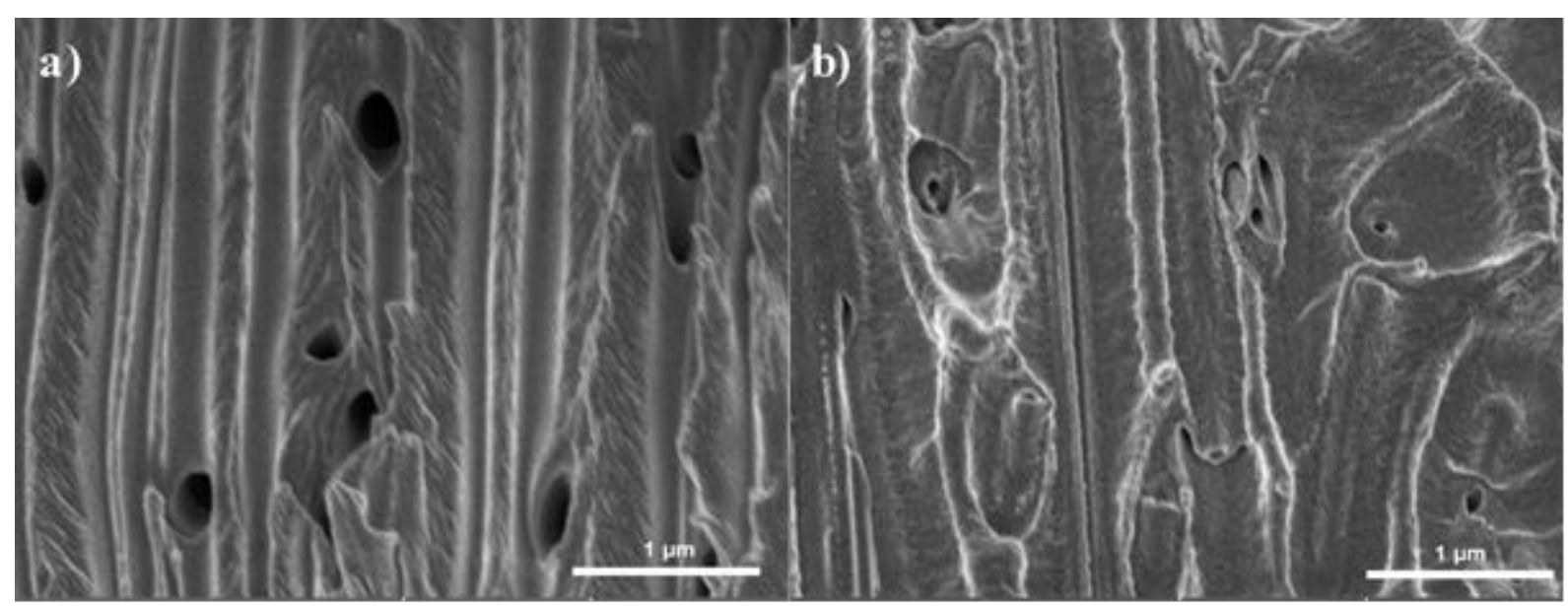

Figure 10. SEM images of the cross-section of the PCM1 (a) and PCM3 (b).

\section{Conclusion}

- The intact original commercial polycarbonate membrane (PCM1) showed only a very small difference between the sorption of $(+)$ - and $(-)-\alpha$-pinene molecules as well as their racemic mixture.

- The use of modified ALD approach for the templating of the polycarbonate membrane with ()- $\alpha$-pinene (PCM2) performed at higher temperatures $\left(90^{\circ} \mathrm{C}\right)$ caused an increase in free volume between polycarbonate chains, which facilitated the diffusion of pinene molecules into the surface layers of the membrane and pore walls, resulting in membrane swelling and pore 
diameter narrowing. In this case, the process caused only a slight change in the difference between the adsorbed/absorbed amount of $(-)-\alpha$-pinene, $(+)-\alpha$-pinene and racemate.

- The ALD of $\mathrm{Al}_{2} \mathrm{O}_{3}$ and the subsequent (-)- $\alpha$-pinene templating of the PCM3 performed at 120 and $90{ }^{\circ} \mathrm{C}$ caused: i) thermal expansion of polymer chains and an increase in the free volume between them, ii) facilitated diffusion of TMA into the free volume between PCM chains and the formation of $\mathrm{Al}_{2} \mathrm{O}_{3}$ on the surface and in the subsurface layer of the PCM, iii) diffusion and imprint of template (-)- $\alpha$-pinene molecules into the free volume of PC and $\mathrm{Al}_{2} \mathrm{O}_{3}$ layer. Compare to the previous case, this procedure led to a significantly higher sorption of $(-)-\alpha-$ pinene compared to the opposite enantiomer and racemate. In contrast, the sorption of the racemate was only slightly higher than the sorption of $(+)-\alpha$-pinene. This indicates that the significantly increased sorption of single (-)- $\alpha$-pinene does not necessarily imply its equivalent preferential sorption from the racemate. It suggests, that the sorption behavior of the racemic mixture is affected by a different thermodynamic and kinetic behavior of the individual enantiomers.

- Nevertheless, the effect of the introduction of chirality by the modified ALD approach of the $\mathrm{Al}_{2} \mathrm{O}_{3}$ pre-coated PCM with (-)- $\alpha$-pinene molecules is clearly demonstrated. We believe that it is worth using this effect in a more convincing arrangement to achieve preferential sorption with the potential to expand the range of membrane separation techniques.

- The presented approach of templating pinene molecules within PCM could be carried out essentially by any vacuum deposition tool that enables dosing and purging of a compound from liquid or solid container. In the present case, ALD tool was used for the pinene templating, as it we operate it and we also used it for ALD of $\mathrm{Al}_{2} \mathrm{O}_{3}$ within PCM. 


\section{AUTHOR INFORMATION}

\section{Corresponding Author}

* Jan M. Macak, E-mail: jan.macak@upce.cz

\section{SUPPORTING INFORMATION}

Kinetic measurements of weight of membranes in time during the sorption of $\alpha$-pinene racemic mixture and individual enantiomers.

\section{Author Contributions}

The manuscript was written through contributions of all authors. All authors have given approval to the final version of the manuscript.

\section{ACKNOWLEDGMENT}

The authors gratefully acknowledge the Czech Science Foundation (20-06264S) and the Ministry of Education, Youth and Sports of the Czech Republic (projects LM2018103, LQ1601 and CZ.02.1.01/0.0/0.0/17_048/0007421) for the financial support.

\section{ABBREVIATIONS}

ALD atomic layer deposition, PCM polycarbonate membrane, 


\section{REFERENCES}

(1) Nguyen, L. A.; He, H.; Pham-Huy, C. Chiral Drugs: An Overview. Int. J. Biomed. Sci. 2006, 2 (2), 85-100.

(2) Blaser, H. U. Chirality and Its Implications for the Pharmaceutical Industry. Rend. Lincei 2013, 24, 213-216. https://doi.org/10.1007/s12210-012-0220-2.

(3) Croci, D. M.; Dalolio, M.; Schaeren, S.; Wasner, M. G.; Mariani, L.; Jost, G. F. Thalidomide Embryopathy as Possible Cause of Anterior Sacral Meningocele: A Case Report. Birth Defects Res. 2017, 109, 1390-1392. https://doi.org/10.1002/bdr2.1124.

(4) Han, J.; Kitagawa, O.; Wzorek, A.; Klika, K. D.; Soloshonok, V. A. The SelfDisproportionation of Enantiomers (SDE): A Menace or an Opportunity? Chem. Sci. 2018, 9 (7), 1718-1739. https://doi.org/10.1039/c7sc05138g.

(5) Zenkevich, I. G.; Pavlovskii, A. A. Effects of the Dynamic Modification of Stationary Phases by Sorbates in Gas Chromatography: The Possibility of Separating Enantiomers in Achiral Systems. Russ. J. Phys. Chem. A 2016, 90, 2110-2118. https://doi.org/10.1134/S0036024416100320.

(6) Sekhon, B. S. Enantioseparation of Chiral Drugs - An Overview. Int. J. PharmTech Res. 2010, 2, 1584-1594.

(7) Pineri, M.; Gebel, G.; Davies, R. J.; Diat, O. Water Sorption-Desorption in Nafion ${ }^{\circledR}$ Membranes at Low Temperature, Probed by Micro X-Ray Diffraction. J. Power Sources 2007, 172, 587-596. https://doi.org/10.1016/j.jpowsour.2007.05.037.

(8) Sanganyado, E.; Lu, Z.; Fu, Q.; Schlenk, D.; Gan, J. Chiral Pharmaceuticals: A Review on Their Environmental Occurrence and Fate Processes. Water Res. 2017, 124, 527-542. https://doi.org/10.1016/j.watres.2017.08.003. 
(9) Lorenz, H.; Seidel-Morgenstern, A. Processes to Separate Enantiomers. Angew. Chemie Int. Ed. 2014, 53 (5), 1218-1250. https://doi.org/10.1002/anie.201302823.

(10) Xie, R.; Chu, L. Y.; Deng, J. G. Membranes and Membrane Processes for Chiral Resolution. Chem. Soc. Rev. 2008, 37, 1243-1263. https://doi.org/10.1039/b713350b.

(11) Higuchi, A.; Tamai, M.; Ko, Y. A.; Tagawa, Y. I.; Wu, Y. H.; Freeman, B. D.; Bing, J. T.; Chang, Y.; Ling, Q. D. Polymeric Membranes for Chiral Separation of Pharmaceuticals and $\begin{array}{llllll}\text { Chemicals. } & \text { Polym. } & \text { Rev. } & \text { 2010, } & 50 & \text { (2), }\end{array}$ https://doi.org/10.1080/15583721003698853.

(12) Otmar, M.; Gaálová, J.; Žitka, J.; Brožová, L.; Cuřínová, P.; Kohout, M.; Hovorka, Š.; Bara, J. E.; Van der Bruggen, B.; Jirsák, J.; Izák, P. Preparation of PSEBS Membranes Bearing (S)-(-)-Methylbenzylamine as Chiral Selector. Eur. Polym. J. 2020, 122, 109381. https://doi.org/10.1016/j.eurpolymj.2019.109381.

(13) Hovorka; Randová, A.; Borbášová, T.; Sysel, P.; Vychodilová, H.; Červenková-Š̉astná, L.; Brožová, L.; Žitka, J.; Storch, J.; Kačírková, M.; Drašar, P.; Izák, P. Permeability and Diffusion Coefficients of Single Methyl Lactate Enantiomers in Nafion ${ }^{\circledR}$ and Cellophane Membranes Measured in Diffusion Cell. Sep. Purif. Technol. 2016, 158, 322-332. https://doi.org/10.1016/j.seppur.2015.12.026.

(14) Xie, S. M.; Wang, W. F.; Ai, P.; Yang, M.; Yuan, L. M. Chiral Separation of (R,S)-2Phenyl-1-Propanol through Cellulose Acetate Butyrate Membranes. J. Memb. Sci. 2008, 321, 293-298. https://doi.org/10.1016/j.memsci.2008.05.011.

(15) Flores-López, L. Z.; Caloca, J.; Rogel-Hernández, E.; Espinoza-Gomez, H. Development of an Enantioselective Membrane from Cellulose Acetate Propionate/Cellulose Acetate, for the Separation of Trans-Stilbene Oxide. Cellulose 2014, 21 (3), 1987-1995. 
https://doi.org/10.1007/s10570-014-0252-0.

(16) Okamoto, Y. Chiral Polymers for Resolution of Enantiomers. J. Polym. Sci. Part A Polym. Chem. 2009, 47, 1731-1739. https://doi.org/10.1002/pola.23215.

(17) Lämmerhofer, M. Chiral Recognition by Enantioselective Liquid Chromatography: Mechanisms and Modern Chiral Stationary Phases. J. Chromatogr. A 2010, 1217, 814-856. https://doi.org/10.1016/j.chroma.2009.10.022.

(18) Cavazzini, A.; Pasti, L.; Massi, A.; Marchetti, N.; Dondi, F. Recent Applications in Chiral High Performance Liquid Chromatography: A Review. Anal. Chim. Acta 2011, 706 (2), 205-222. https://doi.org/10.1016/j.aca.2011.08.038.

(19) Hoek, E. M. V.; Tarabara, V. V.; Yoshikawa, M.; Higuchi, A. Enantioselective Membranes. $\begin{array}{lllll}\text { Encycl. } & \text { Membr. } & \text { Sci. } & \text { Technol. }\end{array}$ https://doi.org/10.1002/9781118522318.emst131.

(20) Kryscio, D. R.; Peppas, N. A. Critical Review and Perspective of Macromolecularly Imprinted Polymers. Acta Biomater. 2012, 8 (2), 461-473. https://doi.org/10.1016/j.actbio.2011.11.005.

(21) Ul-Haq, N.; Park, J. K. Chiral Resolution of Phenylalanine by D-Phe Imprinted Membrane Considering Rejection Property. Bioprocess Biosyst. Eng. 2010, 33 (1), 79-86. https://doi.org/10.1007/s00449-009-0352-7.

(22) Sunsandee, N.; Leepipatpiboon, N.; Ramakul, P.; Pancharoen, U. The Selective Separation of (S)-Amlodipine via a Hollow Fiber Supported Liquid Membrane: Modeling and Experimental Verification. Chem. Eng. J. 2012, 180, 299-308. https://doi.org/10.1016/j.cej.2011.11.068.

(23) Sunsandee, N.; Leepipatpiboon, N.; Ramakul, P.; Wongsawa, T.; Pancharoen, U. The 
Effects of Thermodynamics on Mass Transfer and Enantioseparation of (R,S)-Amlodipine across a Hollow Fiber Supported Liquid Membrane. Sep. Purif. Technol. 2013, 102, 50-61. https://doi.org/10.1016/j.seppur.2012.09.027.

(24) Maximini, A.; Chmiel, H.; Holdik, H.; Maier, N. W. Development of a Supported Liquid Membrane Process for Separating Enantiomers of N-Protected Amino Acid Derivatives. J. Memb. Sci. 2006, 276 (1-2), 221-231. https://doi.org/10.1016/j.memsci.2005.09.050.

(25) Gössi, A.; Riedl, W.; Schuur, B. Enantioseparation with Liquid Membranes. J. Chem. Technol. Biotechnol. 2018, 93 (3), 629-644. https://doi.org/10.1002/jctb.5417.

(26) Kim, J. H.; Kim, J. H.; Jegal, J.; Lee, K. H. Optical Resolution of $\alpha$-Amino Acids through Enantioselective Polymeric Membranes Based on Polysaccharides. J. Memb. Sci. 2003, 213 (1-2), 273-283. https://doi.org/10.1016/S0376-7388(02)00534-3.

(27) Thoelen, C.; De Bruyn, M.; Theunissen, E.; Kondo, Y.; Vankelecom, I. F. J.; Grobet, P.; Yoshikawa, M.; Jacobs, P. A. Membranes Based on Poly( $\gamma$-Methyl-L-Glutamate): Synthesis, Characterization and Use in Chiral Separations. J. Memb. Sci. 2001, 186 (2), 153-163. https://doi.org/10.1016/S0376-7388(00)00687-6.

(28) Van Der Ent, E. M.; Van’t Riet, K.; Keurentjes, J. T. F.; Van Der Padt, A. Design Criteria for Dense Permeation-Selective Membranes for Enantiomer Separations. J. Memb. Sci. 2001, 185 (2), 207-221. https://doi.org/10.1016/S0376-7388(00)00647-5.

(29) Brydson, J. A. Plastics Materials. Butterworth - Heineman 1989.

(30) Strong, A. B. Plastics: Materials and Processing. Prentice Hall 2000.

(31) Shalev, O. L.; Carmiel, Y.; Gottesman, R.; Tirosh, S.; Mastai, Y. Chiral Templating of Alumina Nanofilms by the Atomic Layer Deposition Process. Chem. Commun. 2016, 52 (81), 12072-12075. https://doi.org/10.1039/c6cc05892b. 
(32) Deng, C. H.; Li, T.; Chen, J. H.; Ma, J. G.; Cheng, P. The Electrochemical Discrimination of Pinene Enantiomers by a Cyclodextrin Metal-Organic Framework. Dalt. Trans. 2017, 46 (21), 6830-6834. https://doi.org/10.1039/c7dt00808b.

(33) Elam, J. W.; Routkevitch, D.; Mardilovich, P. P.; George, S. M. Conformal Coating on Ultrahigh-Aspect-Ratio Nanopores of Anodic Alumina by Atomic Layer Deposition. Chem. Mater. 2003, 15 (18), 3507-3517. https://doi.org/10.1021/cm0303080.

(34) Dvorak, F.; Zazpe, R.; Krbal, M.; Sopha, H.; Prikryl, J.; Ng, S.; Hromadko, L.; Bures, F.; Macak, J. M. One-Dimensional Anodic TiO2 Nanotubes Coated by Atomic Layer Deposition: Towards Advanced Applications. Appl. Mater. Today 2019, 14, 1-20. https://doi.org/10.1016/j.apmt.2018.11.005.

(35) Hawkins, J. E.; Armstrong, G. T. Physical and Thermodynamic Properties of Terpenes. III. The Vapor Pressures of $\alpha$-Pinene and $\beta$-Pinene. J. Am. Chem. Soc. 1954, 76 (14), 37563758. https://doi.org/10.1021/ja01643a051.

(36) Nelson, C.; Chickos, J. The Vaporization Enthalpy and Vapor Pressures of Liquid Adamantane, Diamantane and A- and B-Cedrene by Correlation Gas Chromatography. J. Chem. Thermodyn. 2018, 121, 175-186. https://doi.org/10.1016/j.jct.2018.02.016.

(37) Brožová, L.; Žitka, J.; Sysel, P.; Hovorka, Š.; Randová, A.; Storch, J.; Kačírková, M.; Izák, P. Sorption of Single Enantiomers and Racemic Mixture of (+/-)- $\alpha$-Pinene into Nafion Membranes. Desalin. Water Treat. 2015, 55, 2967-2972. https://doi.org/10.1080/19443994.2014.939496.

(38) Brožová, L.; Žitka, J.; Sysel, P.; Hovorka, Š.; Randová, A.; Storch, J.; Kačírková, M.; Izák, P. Stereoselective Behavior of Nafion ${ }^{\circledR}$ Membranes towards (+)- $\alpha$-Pinene and (-)- $\alpha$-Pinene. Chem. Eng. Technol. 2015, 38 (9), 1617-1624. https://doi.org/10.1002/ceat.201400621. 
(39) Roddy. ( 12 ) United States Patent ( 16 ) Patent No .: ( 45 ) Date of Patent: Syst. Method Sel. Transm. Images Interes. To a User 2002, 1 (12), 1-4.

(40) Parsons, G. N.; Atanasov, S. E.; Dandley, E. C.; Devine, C. K.; Gong, B.; Jur, J. S.; Lee, K.; Oldham, C. J.; Peng, Q.; Spagnola, J. C.; Williams, P. S. Mechanisms and Reactions during Atomic Layer Deposition on Polymers. Coord. Chem. Rev. 2013, 257 (23-24), 3323-3331. https://doi.org/10.1016/j.ccr.2013.07.001.

(41) Gong, B.; Parsons, G. N. Quantitative in Situ Infrared Analysis of Reactions between Trimethylaluminum and Polymers during $\mathrm{Al} 2 \mathrm{O} 3$ Atomic Layer Deposition. J. Mater. Chem. 2012, 22 (31), 15672-15682. https://doi.org/10.1039/c2jm32343e.

(42) Sing, K. S. W.; Everett, D. H.; Haul, R. A. W.; Moscou, L.; Pierotti, R. A.; Rouquerol, J. . T. S. T. Reporting Physisorption Data for Gas/Solid Systems. Pure Appl. Chem., 1985, 57 (4), 603-619.

(43) Sadriu, I.; Bouden, S.; Nicolle, J.; Podvorica, F. I.; Bertagna, V.; Berho, C.; Amalric, L.; Vautrin-Ul, C. Molecularly Imprinted Polymer Modified Glassy Carbon Electrodes for the Electrochemical Analysis of Isoproturon in Water. Talanta 2020, 207 (March 2019), 120222. https://doi.org/10.1016/j.talanta.2019.120222.

(44) Watt, I. C. Adsorption-Desorption Hysteresis in Polymers. J. Macromol. Sci. Part A - Chem. 1980, 14, 245-255. https://doi.org/10.1080/00222338008066635.

(45) Vrentas, J. S.; Vrentas, C. M. Hysteresis Effects for Sorption in Glassy Polymers. Macromolecules 1996, 29 (12), 4391-4396. https://doi.org/10.1021/ma950969l.

(46) Jeromenok, J.; Weber, J. Restricted Access: On the Nature of Adsorption/Desorption Hysteresis in Amorphous, Microporous Polymeric Materials. Langmuir 2013, 29 (42), 12982-12989. https://doi.org/10.1021/la402630s. 
(47) Crank, J. Mathematics of Diffusion 2.Ed. Oxford Univ. Press 1957. https://doi.org/10.1073/pnas.082483699. 


\section{Table of contents}

Chirality for enantioseparation of racemates is achieved by modification of polycarbonate membranes by modified ALD approach. As a chiral template for ALD (-)- $\alpha$-pinene was selected due to its optimal volatility and low costs. It was deposited either alone or with the undercoating of $\mathrm{Al}_{2} \mathrm{O}_{3}$ layer. Different sorption performance was achieved for $(-)-\alpha$-pinene, $(+)-\alpha$-pinene on modified and unmodified membranes.

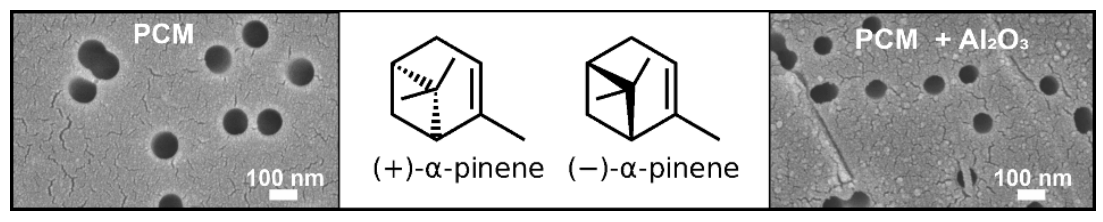

